\title{
Research on Community Supported Agriculture
}

\author{
Hua-Qi CHAI ${ }^{1, a}$, Jie SUN ${ }^{1, b,{ }^{*}}$, Xiao-Min CUI ${ }^{1, c}$ \\ ${ }^{1}$ School of Management, NWPU, Xi 'an, China \\ achaifam@163.com, bsunjiesunshine@126.com, ccuixiaomin123@hotmail.com \\ ${ }^{*}$ Corresponding author
}

Keywords: Community supported agriculture, Ecological, CSA farmers, Share the risk.

\begin{abstract}
Nowdays, the safety of agricultural products becoming increasingly serious, a new way called community supported agriculture (CSA) come into the view of the public. It advocates a healthy and natural lifestyle, hoping to rebuild the harmonious development of rural and urban communities and provide health and safety agricultural products to the community consumers. This article mainly from the overview of CSA, the construction of CSA and the operation of CSA to research about this new mode of agricultural.
\end{abstract}

\section{Introduction}

In recent years, with the rapid development of China's economy, people's income continues to increase. Meanwhile, some food safety accidents affect people's physical and mental health, food security has become a primary topic of concern. At present, the CSA as a new way to provide safe agricultural products and a new idea of agricultural production and operation, quietly appeared in some of our city.The participants from the college students, leading academics to farmer cooperatives, enterprises and government agencies, the CSA come from ideas into practice in China.

\section{Overview of CSA}

CSA is short for "community support agriculture", the concept of CSA is to establish a local food economy system and create an environment, in which farmers and consumers work together to achieve food security and the sustainability of economic, social and natural.The CSA originated in Switzerland in the in the 1970s and get the initial development in Japan. Now, the concept of CSA has spread throughout the world and extend from the original production, economic cooperation to more meaning, such as production safety, pay attention to the environmental protection, advocate healthy, sustainable production, etc.

The core of CSA is sharing and trust.CSA farmers should recognize the importance of value creation, try to build and maintain long relationships with consumers. They must adopt a kind of ecological and sustainable way to grow agricultural products. They should ensure that in the process of the production, chemical fertilizers, pesticides, hormones and other chemicals are not allowed.So there is no pollution to the soil, air and rivers, it is a friendly way to the environment.For community consumers, they should providing guarantee funds to CSA farmers in advance and share the risk in agriculture with CSA farmers. When natural disasters occur, the agricultural harvest a not good and the farmers can also make a live. In return, CSA farmers delivered the local, seasonal food directly to the community consumers.It's a simple idea, but it is good for both and its impact has been profound.

\section{The Construction of CSA}

\section{Integration of multiple resources, diversify participation}

CSA was introduced in 2008, from then different patterns of CSA came into practice in Beijing, Guangxi, Guangdong, Sichuan and other places. Its development is still in its infancy which requires the participation of all aspects of our society. 
- CSA can effectively recover the organic agricultural production and the ecological function, so the government should give enough attention. The government should provide financial support for CSA and strengthen the law for food safety.In addation, the government should provide fund to the research institute for the research and promotion of China's CSA.

- College societies, environmental groups and other organizations, coule take party in the CSA as volunteers in summer and winter vacation. The NGO is also very concerned about food safety and the participation of NGOs is extremely important.

- The media should report about the CSA and the problem of agriculture, countryside and farmers, lead urban residents to pay attention to them. To make them realized that they can be involved in the agriculture and through their efforts they can improve the situation of the farmer.

- Farmers should be dedicated to the production of organic agricultural products and take party in the CSA. Farmers should enrich the CSA farms's activity to let community customers get organic vegetables and happiness at the same time.Build a bridge of communication with community customers to share the risk of agriculture.

\section{Establish ecological agriculture system}

Ecological agriculture should use the principle of ecological symbiosis competition and phase grams. On the physiological and ecological adaptability to make different biological groups of composite production system to establish in a multi-level space, time sequence of the industrial structure, make its can make full use of environmental resources and space.

The farms, biogas and green agriculture should be treated as a whole, so that all aspects of the waste generated can be fully utilization, turning waste into treasure. Through the complex ecology ecological chain cycle, development and utilization of eco-agriculture demonstration garden manure not only turning waste into treasure, solve the production of energy, nutrients, fertilizer problems, but also reduce environmental pollution and to prevent the spread of the disease with a high social and economic benefits.

\section{Build multi-functional ecological agriculture garden}

Although the emergence of the CSA because of the attention to food safety and on the land in the process of urbanization, but we also worth looking forward to the development of tourism in CSA. In different regions, customers will have different experience:

- In the farming culture area, community customers can enjoy the show about the farming culture for thousands of years to understand the way of farming, land system. It can make customers feel the wisdom and great strength of our ancestors.

- Local custom area using small courtyard and pond to build a local landscape.Here, visitors can fish, picnic and experience the rural culture.It is a very good way to relax and close to the nature.

- Farming areas planted a variety of vegetables and a variety of fruits, community consumers can take party in the planting activities and experience the hardships and fun from growing.

- Eco-restaurant is an all-weather, all-round three-dimensional green space, in which community customers can enjoy the ecological vegetables, either family dining or held a banquet is a good choice.

\section{The operation of the CSA}

\section{The circulation of agricultural products}

Compared with the traditional distribution channels of agricultural products, the CSA pays attention to the ecology of the whole process from field to table and try to make the chain to be short.

It advocates the concept of "local production, local consumption", cancel the seller in the middle of the link which reduces the cost, reduces the storage logistics, long-distance transportation, etc. This makes the environment and local food economy and community with sustainability. 
CSA strengthen the popularization of knowledge of modern organic agriculture and the configuration of production equipment. Farmers and consumers get together to negotiate, according to the need for production. This ensures the output of production and market demand is synchronous whih it coule effectively reduces the cost of organic farmers and there is no need to accept the market price passively. At the same time, community consumers can take party in farming, it can make them close to nature, enjoy the fun of labor and harvest and they can also eat safety food and vegetables at the same time. Thus, for consumers and farmers can get the benefits. The circulation of agricultural products is indicated in Fig. 1.

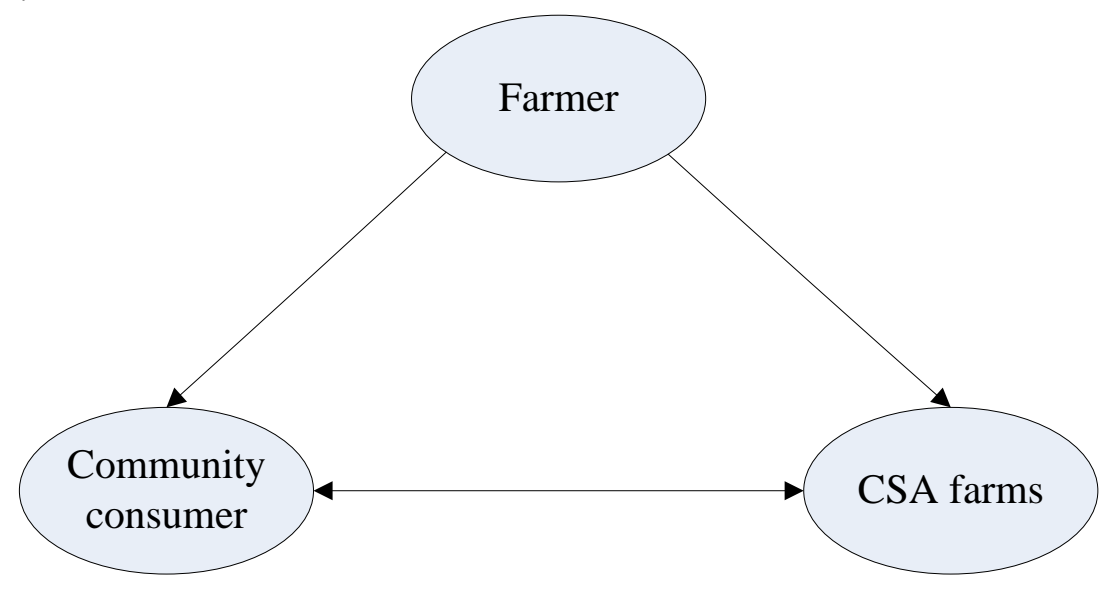

Fig. 1.The circulation of agricultural products

\section{The regulatory of CSA}

At present, the main method of the government to solve the problem of food safety is to strengthen the government's regulation. But it turns out that regulation is so dense, the cost is so great that the effect is not obvious. Konstantinos Gian - nakas from the perspective of the information asymmetry had analyzed the behavior of consumers in the organic food market and pointed out that the organic food certification mark can't deliver enough information, asymmetric information may lead to market failure.

The CSA realized that the food regulatory system ignores the significance of the social forces and the market. In order to guarantee the safety of the food, the CSA set up a multiple supervision system composed by the government, the social organizations, the community consumers and the media. The regulatory of CSA are indicated in Fig. 2.

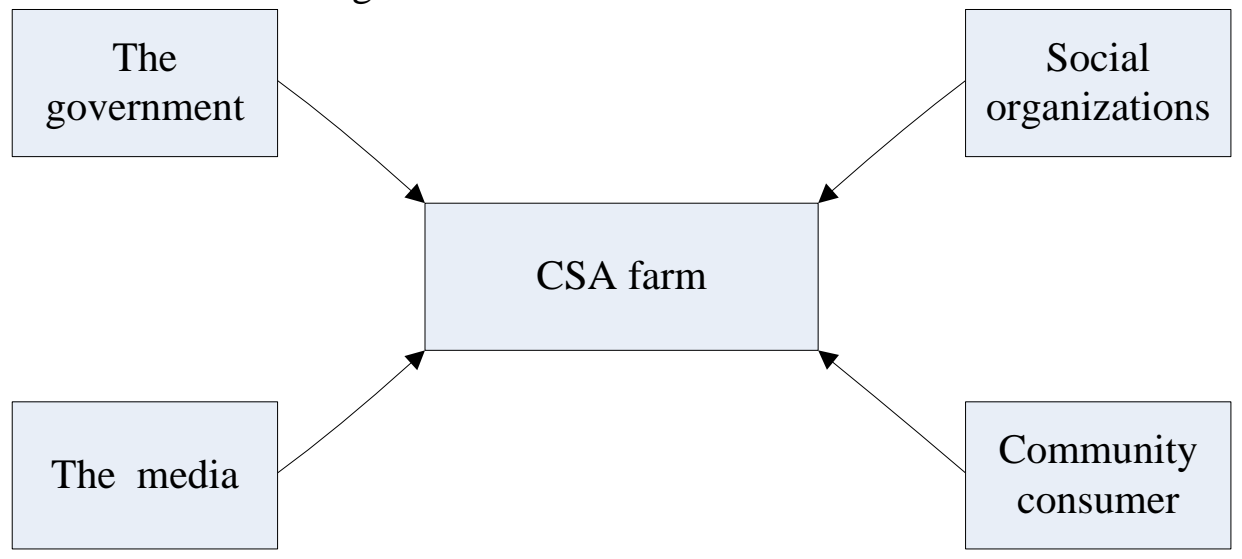

Fig. 2.The regulatory of CSA

\section{The operation of eco-tourism}

In recent years, as incomes rise, more and more people are no longer satisfied merely sightseeing, vacation and other traditional forms of tourism. Eco-tourism is the new way to travel that visitors can take party in and learn something. It is based on CSA, through the city residents to participate in 
agricultural labor to get organic agricultural products and an unprecedented agricultural experience.It consists of a series of activities, for example, introduced the farming culture, introduced the local customs, allow consumers to participate in farming and enjoy meals in the eco-restaurant.

Through a series of activities for consumers to understand the farmer's pressure to survival, the production of crops, the production cost of organic agricultural products, to experience a healthy lifestyle and so that consumers could understand, accept and support CSA. The operation of eco-tourism is indicated in Fig. 3.

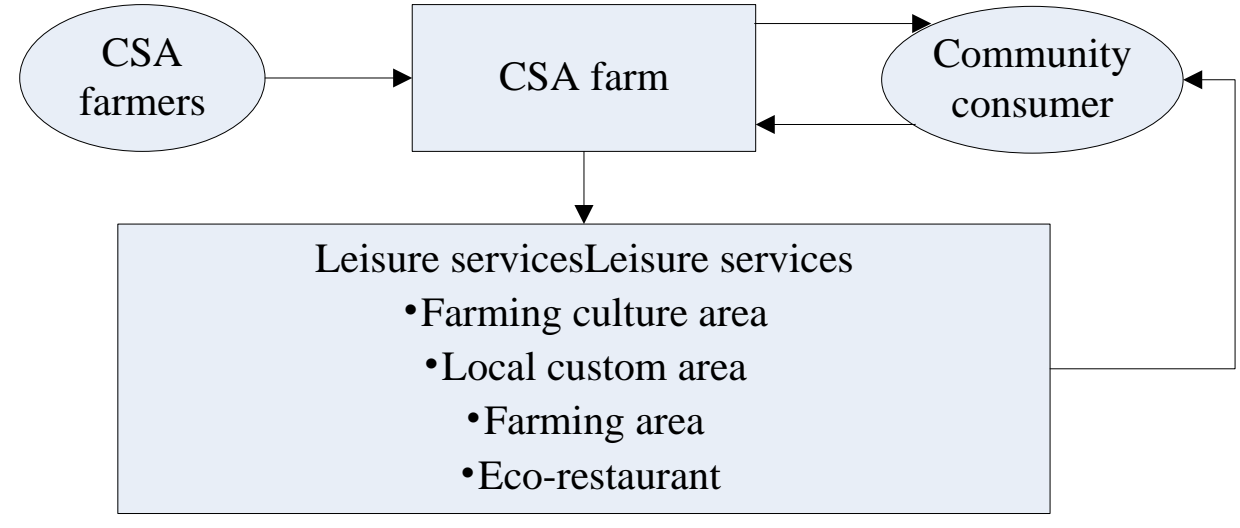

Fig. 3.The operation of eco-tourism

\section{Conclusion}

Under the background that the current situation of food safety is not good, there is no doubt that CSA model provides a feasible solution. CSA through the way of establish mutual trust and cooperation relationship between CSA farmers and community consumers to share the risk of agricultural productions and market to ensure the safety of the agricultural productions. At the same time, it also played a positive role in protecting the environment, developing ecological tourism and promoting the harmonious development of society. Can CSA fully popularized in China or not? It is still need the government's guidance and the participation of more farmers, NGOs and urban communities.

CSA arises at the historic moment, it provides a new way of thinking for improving the quality of agricultural products, providing safety food and building environment-friendly agriculture.

\section{References}

[1] Hayden, J. D. Buck, Doing community supported agriculture: Tactile space, affect and effects of membership.Geoforum 43: 332-341. (2012)

[2] Galt, R.E. Counting and mapping community supportedagriculture (CSA) in the United States and California: Contributions from critical cartography/GIS. Acme: An Internationale-Journal for Critical Geographies 10(2): 131-162 (2011)

[3] Schnell, S.M. The local traveler: Farming, food, and place in state and provincial tourism guides, 1993-2008. Journal of Cultural Geography 28(2): 281-310 (2011)

[4] Alternative food geographies: Representation and practice, ed. D. Maye, L.Holloway, and M. Kneafsey, 255-272. Oxford: Elsevier Science. (2007)

[5] Ostrom, M. Everyday meanings of local food: Views from home and field. Journal of the Community Development Society 37(1): 65-78. (2006)

[6] DeLind, L.B. Of bodies, place, and culture: Re-situating local food. Journal of Agricultural and Environmental Ethics 19:121-146. (2006) 
[7] Charles, L. Animating community supported agriculture in North East England: Striving for a 'caring practice'. Journal of Rural Studies 27: 362-371. (2011)

[8] Wells, B., S. Gradwell. "Growing food, growing community: Community supported agriculture in rural Iowa”.Community Development Journal 34(1): 38-46. (1999)

[9] Schnell, S.M. Food with a farmer's face: Community-supported agriculture in the United States. Geographical Review 97:550-564. (2007)

[10] Casey, E.S. Between geography and philosophy: What does it mean to be in the place-world? Annals of the Association of American Geographers 91(4): 683-693. (2001)

[11] Kolodinsky, J.M. Factors influencing the decision to join a community supported agriculture (CSA) farm.Journal of Sustainable Agriculture 10(2/3): 129-141. (1997) 